\title{
Effect of Vitex agnus Extract on MNU Induced Mammary Tumor of Sprague Dawley Rats
}

\author{
Maninder Kour ${ }^{1}$, Vinodini Nithyananda Madom Anantharaya ${ }^{1}$, Kumar Megur Ramakrishna Bhat ${ }^{2}$, Shrijeet Chakraborti ${ }^{3}$, Bhagyalakshmi \\ Kodavanji ${ }^{1}$ \\ 'Department of Physiology, KMC Mangalore, Manipal University, Karnataka, INDIA. \\ ${ }^{2}$ Department of Anatomy, Raas Al Khaimah, UAE. \\ ${ }^{3}$ Department of Pathology, KMC Mangalore, Manipal University, Karnataka, INDIA.
}

\begin{abstract}
Background: Breast cancer is one of the most serious and life taking etiologies of the present time. The cause and treatment of breast cancer still remains the major concern of medical and health sciences. The Vitex agnus also known as Vitex agnus castus(VAC) or Vitex nirgundi is used for many reproductive problems of females and widely used for the treatment of pre-menstrual stress syndrome and cyclical breast pain. The Vitex agnus extract is used in the present study to see its anticancer effect in mammary tumors. The objective of the study was to investigate the in-vivo anticancer effect of hydroalcoholic extract of Vitex agnus in ameliorating the mammary tumor of the SD rats. Methodology: A 30 day old inbred Sprague dawley (SD) female rats of body weight 70-80 grams were taken for this study. The rats were induced with MNU for mammary tumor development. After the development of palpable and visible tumor the rats were given a hydroalcoholic extract of Vitex agnus. Serum MDA and GSH were measured to check the pro and antioxidant potential of Vitex agnus. Results: Histopathological findings showed the regression features in the tumor of the rats treated with Vitex agnus extract indicating the positive
\end{abstract}

treatment of mammary tumor and improved oxidative status of the tissue was evident by increase in the levels of GSH and decreased levels of serum MDA levels which in turn is an indicator of reduced oxidative stress of the tissue. Conclusion: Therefore, this study suggests that Vitex agnus extract can be useful for the treatment as well as improvement of oxidative status of the mammary tumor tissue.

Key words: Breast Cancer, Vitex agnus Castus, Histopathology, GSH, MDA, Sprague Dawley.

Correspondence :

Dr. Vinodini NA, Associate Professor, Department of Physiology, KMC Mangalore, Manipal University, Karnataka, INDIA.

Phone no: +91 9448214870

Email: vinodini.na@manipal.edu

DOI: 10.5530/jyp.2017.9.73

\section{INTRODUCTION}

Breast cancer is one of the most common cancers with over one million cases reported worldwide. It accounts up to $30 \%$ of all the cancers reported in female's worldwide. ${ }^{1}$ Regardless of having advanced treatments, the disease continues to have the highest rate of treatment failure due to tumor resistance, both intrinsic and acquired. ${ }^{2}$ Many treatment strategies have been applied for the best results to ameliorate the cancer, but none has shown any significant results so far. Natural products have long been an important source for the treatment of different types of cancer. More than a thousand plants have been found to possess significant anticancer properties. ${ }^{3}$ Over $60 \%$ of currently used anticancer agents are derived from natural sources. ${ }^{4}$ The Vitex agnus castus (VAC) is a shrub found in central Europe and central Asia has brown or black colored pepper like seeds having significant levels of herbal and medicinal properties. ${ }^{5}$ It is a well-known herb used for the treatment of female reproductive problem, especially pre-menstrual syndrome and certain endocrine related problems. ${ }^{6}$ Studies reported that the fruit of this plant contains phenolic compounds like terpenes, flavonoids and aetheric oils, etc. ${ }^{7}$ Further studies on it showed that ethanolic extract from dried ripe VAC fruits displays cytotoxic activity against six human cell lines from different cancer tissue origins. ${ }^{8}$ Studies for antioxidant activity in the past have shown that decreased GSH levels are indicator of cell viability along-with increased MDA levels showing marked cell proliferation in tumor tissues whereas decreased levels of the same are indicator improved oxidative status of the tissue. From the recent literature, it is evident that ethanolic fruit extract of the VAC has shown some anticancer effects in, in-vitro studies and there is no recent data suggesting the anticancer property in vivo. Therefore, this study was conducted to elucidate the anticancer effect of the Vitex agnus seed extract along-with its antioxidant activity by estimating GSH and MDA levels on induced mammary tumor of SD rats in an in-vivo study.

\section{MATERIALS AND METHODS}

\section{Animals}

After obtaining the permission from the institutional ethical committee, healthy, 30 days old inbred Sprague Dawley female rats of body weight 70-80 grams were taken for this study. Animals were maintained according to prescribed guidelines of a committee for control and supervision of experts on animals (CPCSEA), Govt. Of India, for the use of laboratory animals. All animals were maintained under normal day-night environment in temperature controlled institutional animal house. Animals were housed in polypropylene cages; paddy husk was used for bedding. Animals were given water ad libitum and standard rat feed pellet was used for feeding.

\section{Induction of tumor}

\section{Preparation of the carcinogen}

Mammary tumor was induced by injecting N-Methyl-N-Nitrosourea dissolved in normal saline with $\mathrm{pH}-4$ maintained by adding $3 \%$ glacial acetic acid. The SD rats were given a single intraperitoneal dose of 
Table1: Treatment with Vitex agnus plant extract on MNU induced mammary tumor

\begin{tabular}{|c|c|c|c|c|c|}
\hline SL no. & Rat weight(g) & $\begin{array}{c}\text { Concentration of MNU } \\
(50 \mathrm{mg} / \mathrm{kgbw})\end{array}$ & $\begin{array}{l}\text { Presence of tumor } \\
\text { (after } 5 \text { months) }\end{array}$ & $\begin{array}{l}\text { Weight of the rat } \\
\text { with tumor(g) }\end{array}$ & $\begin{array}{l}\text { Concentration of plant } \\
\text { extract }(200 \mathrm{mg} / \mathrm{kgbw})\end{array}$ \\
\hline Rat 1 & 97.30 & 4.86 & + & 248 & 49.6 \\
\hline Rat 2 & 114.70 & 5.73 & + & 255 & 51 \\
\hline Rat 3 & 100.0 & 5.00 & + & 270 & 54 \\
\hline Rat 4 & 108.90 & 5.44 & + & 265 & 53 \\
\hline Rat 5 & 90.70 & 4.35 & + & 270 & 54 \\
\hline Rat 6 & 110.00 & 5.50 & + & 254 & 51 \\
\hline
\end{tabular}

$+=$ Presence of solid malignant tumor

$50 \mathrm{mg} / \mathrm{kg}$ bw of MNU and kept for observation for the mammary tumor development (Table 1).

\section{Collection of Plant Material}

Air dried seeds of Vitex agnus castus plants was collected from Vijay nagar; Mysore, Karnataka.

\section{Preparation of Vitex agnus extract}

Hydroalcoholic extract of VAC was prepared using 1:1 ratio of methanol and water using soxhlet apparatus. The dosage was selected based on previous literature. $200 \mathrm{mg} / \mathrm{kgbw}$ of the extract was administered orally for 15 days.

\section{Histopathology}

Histopathological section of the mammary tumor of the SD-rats treated with / without plant extract was done on the sixteenth day after finishing the treatment plan. The rats were anesthetized and the tumor was excised from the mammary region for the same. The tumor tissue was kept at $10 \%$ buffered formalin and then sectioned for Heamatoxylin and Eosin staining.

\section{Anti-Oxidant Studies}

\section{Reduced glutathione (GSH)}

The samples $(0.5 \mathrm{ml}$ of Serum) were treated with $1.5 \mathrm{~mL}$ of precipitating solution and kept for 10 minutes for the precipitation to complete. The solutions are then filtered through a whatmann No.1 filter paper. $500 \mu \mathrm{L}$ of the filtrate is taken and to this $2 \mathrm{~mL}$ of phosphate solution and $250 \mu \mathrm{L}$ of DTNB solution is added. Simultaneously a blank is maintained containing $200 \mu \mathrm{L}$ of distilled water, $300 \mu \mathrm{L}$ of precipitating solution, $2 \mathrm{~mL}$ of phosphate solution and $250 \mu \mathrm{L}$ of DTNB. The intensity of the yellow color formed is spectrophotometrically read immediately (within ten minutes) at $412 \mathrm{~nm}$ against the blank.

\section{Lipid Peroxidation (LPO)}

Serum- $100 \mu \mathrm{L}$ serum is diluted to $500 \mu \mathrm{L}$ with distilled water. To the diluted sample $1 \mathrm{~mL}$ of TCA-TBA-HCl reagent is added and vortex is done for 2 minutes. The samples are kept in boiling water bath for 15 minutes. The reaction mixture is cooled and centrifuged. The supernatant is taken and the optical density of the pink colour formed is read at $535 \mathrm{~nm}$.

\section{Statistics}

Statistical analysis was performed in SPSS Version 20.0 All results were expressed as mean \pm Standard Deviation (SD). Group comparisons were done by using ANNOVA followed by Tukey's multiple comparison test, $\mathrm{p}<0.05$ was considered significant.
Table 2: Effect of Vitex treatment on Antioxidant parameters

\begin{tabular}{ccccc}
\hline Parameters & Control & $\begin{array}{c}\text { Tumor } \\
\text { induced }\end{array}$ & $\begin{array}{c}\text { Vitex } \\
\text { treated }\end{array}$ & p-value \\
\hline $\mathrm{GSH}(\mu \mathrm{mol} / \mathrm{ml})$ & $11.33 \pm 1.15$ & $2.63 \pm 0.77$ & $14.21 \pm 0.84$ & $<0.001^{* \#}$ \\
$\mathrm{MDA}(\mu \mathrm{mol} / \mathrm{ml})$ & $0.61 \pm 0.18$ & $1.56 \pm 1.03$ & $0.55 \pm 0.17$ & $<0.05^{* \text { \# }}$ \\
\hline
\end{tabular}

Results were expressed as mean \pm SD

Symbols * \# indicate comparison between Tumor induced vs Control, and Tumor induced vs Vitex treatment groups respectively.

\section{RESULTS}

\section{Antioxidant Estimations}

The antioxidant status (table 2) was found to be significantly lowered in tumor induced group and significantly increased in Vitex agnus treated group in mammary carcinoma bearing rats when compared with normal control rats. The MDA levels were found to be increased in tumor induced groups as compared to control and treated group showing increased lipid peroxidation in tumor tissue.

Histopathological section The SD rats without VAC extract showed infiltrating ductal carcinoma (IDC) with sheets of malignant ductal cells and stromal infiltration, tubular adenosis and malignant ductal cells infiltrating the squamous epithelial layer of the skin. (Fig: 1a \& b). Whereas, the rats treated with hydroalcoholic fruit extract of VAC showed atrophic ducts and absence of malignant tumor cells and fibroblastic proliferation in the stroma and the presence of foamy macrophages in the stroma indicating the regression of the tumor. (Fig $2 \mathrm{a} \& \mathrm{~b}$ )

\section{DISCUSSION}

Plant-derived natural products have received considerable attention in medical literature in recent years, due to their diverse pharmacological properties, such as antioxidant and anticancer activity. ${ }^{9}$ VAC is an herb, used by women all over the world for ameliorating the symptoms of pre-menstrual syndrome. ${ }^{10}$ VAC extract is a popular herbal treatment predominantly used for wide range of female reproductive conditions. Animal studies suggest that VAC extract may increase Estrogen and Progesterone levels. VAC extract has limited use outside its effects on premenstrual syndrome.

Lately, in-vitro studies have shown that plant extract can be used for the treatment of female related cancers, such as breast cancer. Several studies done on different cancer cell lines have shown effective treatment with different plant extracts. The cell line studies have mostly concentrated on DNA damage, cytotoxicity through apoptosis and free radical scavenging activitiy. ${ }^{11}$

The presence of mammary tumor (benign or malignant) was histopathologically confirmed. Antitumor activity of methanolic extract of seeds of 


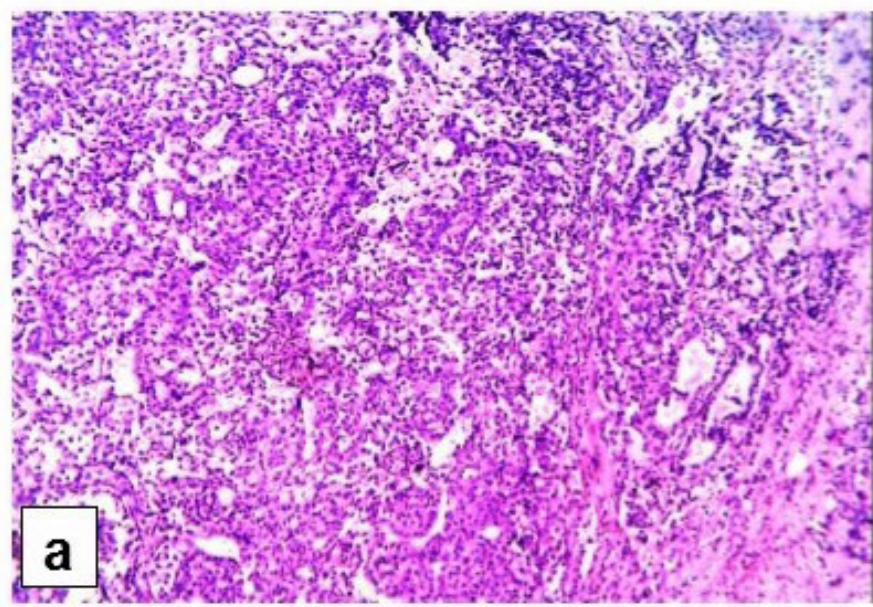

Figure 1: Infiltrating Ductal Carcinoma - a: Sheets of malignant ductal cells

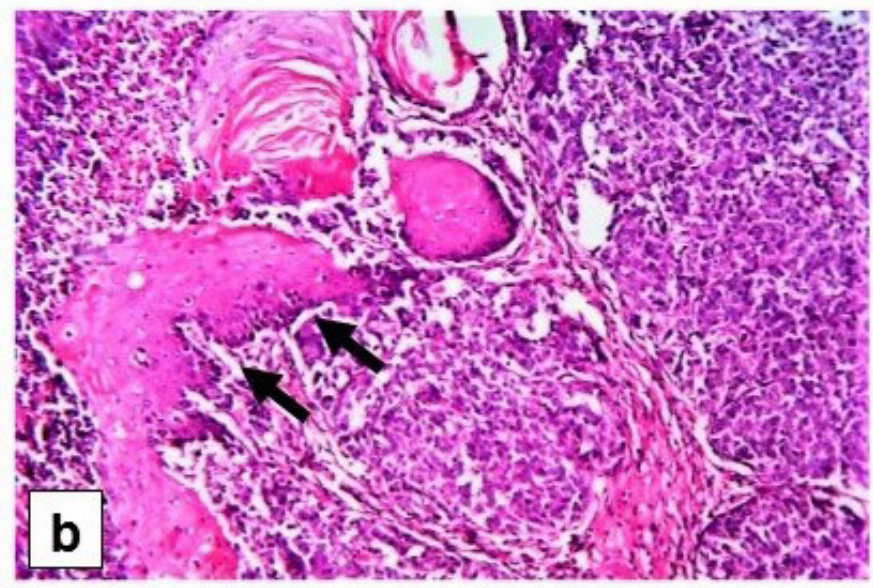

Figure 1 b: Infiltrating Ductal Carcinoma -: Sheets of malignant ductal cells infiltrating the squamous epithelial cell layer of the skin (black arrow).

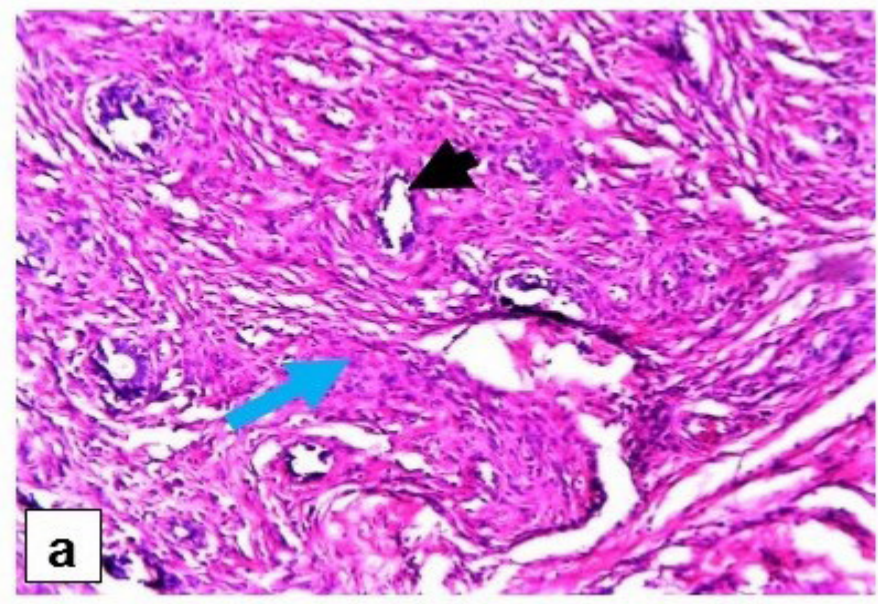

Figure 2: Effect of Vitex agnus plant extract on the malignant tumour tumour regression is indicated by a: atrophic ducts (black arrow head), absence of malignant tumour cells and fibroblastic proliferation (blue arrow) in the stroma

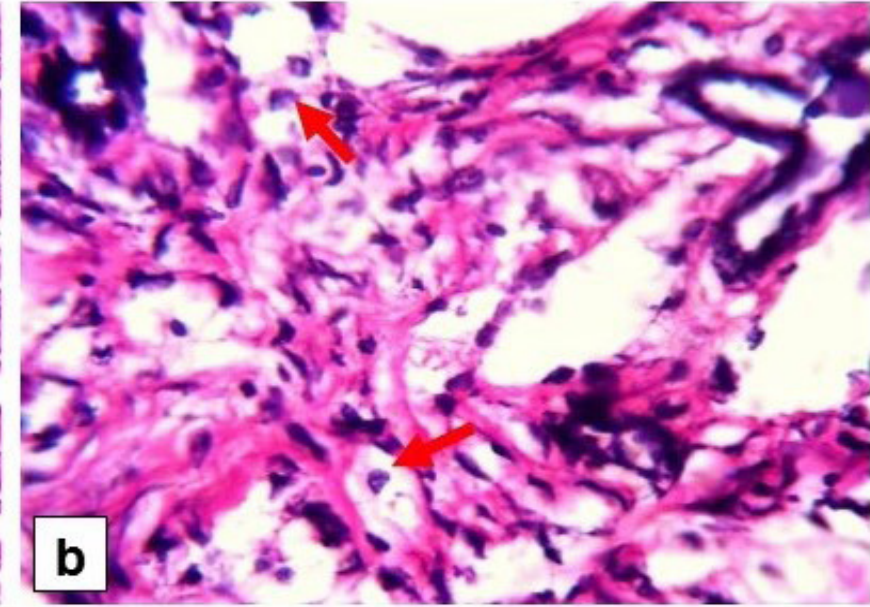

Figure $\mathbf{2 b}$ : foamy macrophages in the stroma (red arrow).

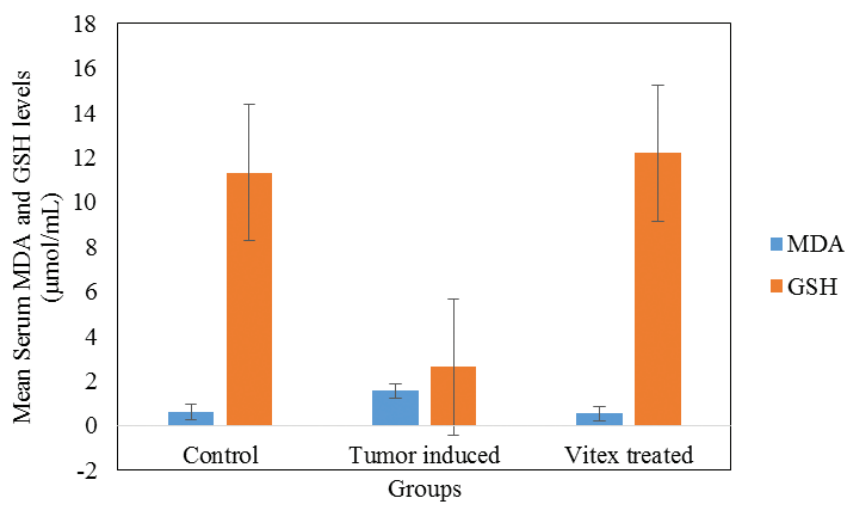

Graph 1: Effect of Vitex treatment on Antioxidant parameters (MDA \& GSH)

Vitex agnus has been evaluated by treating the tumor induced animals for 15 days. In this study tumor regression was observed by the histopathological sectioning showing atrophic ducts and absence of malignant tumor cells and fibroblastic proliferation in the stroma. Also, the presence of foamy macrophages or histocytes was observed which indicates the tumor regression (Fig: 2 a \&b). VAC has diverse pharmacological properties, including antioxidant and anti-cancer activity.

It is known that GSH plays a critical role in maintaining cell viability. The observed lower level of glutathione in mammary carcinoma rats may result in enhanced lipid peroxidation and excess utilization of this antioxidant for tumour cell proliferation, which is in accordance with earlier reports. ${ }^{12}$

In our study, Vitex agnus treatment improved serum GSH and decreased lipid peroxidation which was evident by low serum MDA levels. This gives an indication of the improved oxidative state of the mammary tissue indicating decreased cell proliferation of the tumor tissue. Several mammary tumor cell line studies of the seed extract have shown antioxidant, cytotoxic, DNA damaging and apoptotic activity. A study with methanolic extract of VAC seeds reported its phytochemical properties showing potent anticancer compounds. Isolated compounds for its anticancer activity still need to be identified. The results of our study are in accordance with previous in vitro studies conducted to find out the 
role of antioxidant activity and anticancer effect of VAC seed extracts on MCF-7 breast cancer cell lines. The phenolic compounds present in the fruits can be the reason for the regression of the mammary tumor which was observed in our study. Therefore, our study suggests that the plant extract can be used for the treatment of mammary carcinoma and in-turn helpful in the regression of the mammary tumor. Further studies are needed to confirm the active constituents responsible for the observed activity. As the treatment plan was for only 15 days, the chronic effects of Vitex agnus treatment in complete mammary tumor regression needs to be further evaluated.

\section{CONCLUSION}

The antioxidant estimations and histopathological findings show that the plant extract was helpful in the regression of the mammary tumor. Therefore, VAC extract can be used as an alternative therapeutic measure for breast cancer treatment in the future.

\section{ACKNOWLEDGEMENT}

We are thankful to Manipal University for supporting the Research work. We are also thankful to Dept of Physiology, KMC Mangalore for providing the laboratory and instruments for conducting the experiments.

\section{CONFLICT OF INTEREST}

NIL.

\section{ABBREVIATION USED}

VAC: Vitex agnus castus; SD: Sprague dawley; MNU: N-Methyl-NNitrosourea; CPCSEA: Committee for Control and Supervision of Experts on Animals; MDA: Malonaldehyle; GSH: Reduced Gluthathione;
DTNB: 5'5'DiThio-bis-Nitrobenzoic Acid; TCA: Trichloroacetic acid; TBA: Thiobarbituric acid; HCl: Hydrochori acid.

\section{REFERENCES}

1. Sethi BK, Chanukya GV, Nagesh VS. Prolactin and cancer: Has the orphan finally found a home?. Indian journal of endocrinology and metabolism. 2012;16(8):195.

2. Greenlee RT, Murray T, Bolden S, Wingo PA. Cancer statistics, 2000. CA: a cancer journal for clinicians. 2000;50(1):7-33. https://doi.org/10.3322/canjclin.50.1.7.

3. LIAO F. Cytotoxicity, apoptosis induction, and mitotic arrest by a novel podophyllotoxin glucoside, 4DPG, in tumor cells. Acta Pharmacologica Sinica. 2005:26(8):1000-8. https://doi.org/10.1111/j.1745-7254.2005.00148.x; PMid:16038635

4. Cragg GM, Newman DJ, Snader KM. Natural products in drug discovery and development. Journal of natural products. 1997;60(1):52-60. https://doi. org/10.1021/np9604893; PMid:9014353.

5. Böhnert KJ, Hahn G. Phytotherapie in Gynäkologie und Geburtshilfe: Vitex Agnus-castus (Keuschlamm). Erfahrungsheilkunde. 1990;39:494-502.

6. Jarry H, Spengler B, Wuttke W, Christoffel V. In vitro assays for bioactivity-guided isolation of endocrine active compounds in Vitex agnus-castus. Maturitas. 2006:55:S26-36. https://doi.org/10.1016/..maturitas.2006.06.014.

7. Odenthal KP. Vitex agnus castus L.,--traditional drug and actual indications. Phytotherapy Research. 1998;12(S1). https://doi.org/10.1002/(SICI)10991573(1998)12:1+<S160::AID-PTR283>3.0.CO:2-Y.

8. Ohyama K, Akaike T, Hirobe C, Yamakawa T. Cytotoxicity and apoptotic inducibility of Vitex agnus-castus fruit extract in cultured human normal and cancer cells and effect on growth. Biological and Pharmaceutical Bulletin. 2003;26(1):10-8. https://doi.org/10.1248/bpb.26.10; PMid:12520164

9. Mazzio EA, Soliman KF. In vitro screening for the tumoricidal properties of international medicinal herbs. Phytotherapy research. 2009;23(3):385-98. https://doi. org/10.1002/ptr.2636; PMid:18844256 PMCid:PMC2650746.

10. Dante G, Facchinetti F. Herbal treatments for alleviating premenstrual symptoms: a systematic review. Journal of Psychosomatic Obstetrics \& Gynecology. 2011;32(1):42-51. https://doi.org/10.3109/0167482X.2010.538102; PMid:21171936.

11. Sultan Aslantürk Ö, Askın Çelik T. Antioxidant activity and anticancer effect of Vitex agnus-castus L.(Verbenaceae) seed extracts on MCF-7 breast cancer cells. Caryologia: International Journal of Cytology, Cytosystematics and Cytogenetics. 2013;66(3):257-67. https://doi.org/10.1080/00087114.2013.850797.

12. Comporti M. Three models of free radical-induced cell injury. Chemico-biologica interactions. 1989;72(1-2):1-56. https://doi.org/10.1016/0009-2797(89)90016-1.

Article History: Submission Date : 11-01-2017; Revised Date : 08-04-2017; Acceptance Date : 04-05-2017.

Cite this article: Kour M, Anantharaya VNM, Bhat KMR, Chakraborti S, Kodavanji B. Effect of Vitex agnus Extract on MNU Induced Mammary Tumor of Sprague Dawley Rats. J Young Pharm. 2017:9(3):367-70. 